\title{
Evaluation of Abdominal Expiratory Muscle Thickness Pattern, Diaphragmatic Excursion, and Lung Ultrasound Score in Critically Ill Patients and Their Association with Weaning Patterns: A Prospective Observational Study
}

\author{
Vedaghosh Amara ${ }^{1} \odot$, Vishwas $\mathrm{P}^{2} \odot$, Sagar S Maddani ${ }^{3} \odot$, Srikant Natarajan ${ }^{4} \odot$, Souvik Chaudhuri ${ }^{5} \odot$
}

\begin{abstract}
Introduction: The expiratory muscles are an indispensable component of respiratory function in critically ill patients, yet is often overlooked. We evaluated the association of abdominal expiratory muscles thickness pattern with weaning.

Materials and methods: This was a single-center, prospective observational study done on 81 adult mechanically ventilated patients who underwent the weaning process.

Results: Sixteen patients had simple weaning and 65 patients had either difficult or prolonged weaning. The mean and standard deviation (SD) of the thickness of expiratory abdominal muscles-rectus abdominis (RA), internal oblique (IO), external oblique (EO), and transversus abdominis (TA) were significantly more in patients with simple weaning than those with difficult or prolonged weaning. The receiver operating curve (ROC) of expiratory muscles showed RA, IO, EO, TA cut-offs $0.638,0.492,0.315$, and $0.253 \mathrm{~cm}$, respectively, to predict simple weaning. The pattern of expiratory muscle thickness $\mathrm{RA}>\mathrm{IO}>\mathrm{EO}>\mathrm{TA}$ was maintained in both simple and difficult/prolonged weaning groups $(p=0.362)$. The ROC of diaphragmatic excursion (DE) for predicting simple weaning had cut-off $1.79 \mathrm{~cm}$. The lung ultrasound score (LUS) was $5.75 \pm 3.32$ in the simple weaning group, compared to $9.71 \pm 5.18$ in the difficult/prolonged weaning group $(p=0.005)$.

Conclusion: Abdominal expiratory muscles were significantly thicker in patients with simple weaning compared to those with difficult or prolonged weaning. The pattern of expiratory muscle thickness followed the pattern of RA $>I O>E O>T A$ in both simple weaning and difficult or prolonged weaning groups. DE $>1.79 \mathrm{~cm}$ predicted simple weaning and LUS was significantly lesser in patients with simple weaning (CTRI/2020/11/028895).

Keywords: Diaphragmatic excursion, Expiratory abdominal muscles, Expiratory muscle thickness pattern, External oblique, Internal oblique, Rectus abdominis, Transversus abdominis.

Indian Journal of Critical Care Medicine (2022): 10.5005/jp-journals-10071-24125
\end{abstract}

\section{INTRODUCTION}

Expiratory muscles consist of the rib cage muscles (internal intercostals and triangularis sterni) and the abdominal musclesrectus abdominis (RA), internal oblique (IO), external oblique (EO), and transversus abdominis (TA). Even though literature is replete with studies on inspiratory muscles, especially diaphragm and its role in weaning, the expiratory muscles have often been overlooked. ${ }^{1-3}$ The role of the expiratory muscles assumes significance whenever there is an increased work of respiration on the inspiratory muscles, like in critically ill sepsis patients, those undergoing weaning or during strenuous physical activities in healthy individuals. ' Whenever there is an increased demand on the inspiratory muscles, like in patients in the intensive care unit (ICU), the expiratory muscles of the abdomen are recruited. ${ }^{1,4}$ These muscles are recruited for the expiratory work in a particular order. The TA is the first abdominal expiratory muscle to be recruited. ${ }^{1,5}$ Thereafter, the $I O$ is recruited, then the EO, and finally the RA. ${ }^{1,5}$ In noncritically ill patients, the thickness of the expiratory abdominal muscles has a definite order, RA $>I O>E O>$ TA. ${ }^{1}$ The thickness of TA muscle correlates to the expiratory pressure developed as well as the electrical activity generated in the muscle. 'We wanted to determine if there was a difference in the expiratory muscle thickness and the pattern of this thickness (RA $>I O>E O>T A$ ) in patients with simple weaning vs difficult or prolonged weaning. The
1-3,5 Department of Critical Care Medicine, Kasturba Medical College, Manipal, Manipal Academy of Higher Education, Manipal, Karnataka, India

${ }^{4}$ Department of Oral Pathology and Microbiology, Manipal College of Dental Sciences, Mangaluru, Manipal Academy of Higher Education, Manipal, Karnataka, India

Corresponding Author: Souvik Chaudhuri, Department of Critical Care Medicine, Kasturba Medical College, Manipal, Manipal Academy of Higher Education, Manipal, Karnataka, India, Phone: +91 9937178620, e-mail: souvikchaudhuri1207@gmail.com

How to cite this article: Amara V, Vishwas P, Maddani SS, Natarajan S, Chaudhuri S. Evaluation of Abdominal Expiratory Muscle Thickness Pattern, Diaphragmatic Excursion, and Lung Ultrasound Score in Critically III Patients and Their Association with Weaning Patterns: A Prospective Observational Study. Indian J Crit Care Med 2022;26(3): 307-313.

Source of support: Nil

Conflict of interest: None

hypothesis is that patients with simple weaning will have thicker abdominal expiratory muscles and have the thickness pattern of $\mathrm{RA}>\mathrm{IO}>\mathrm{EO}>\mathrm{TA}$ maintained, as compared to patients with difficult or prolonged weaning. The research question which we 
wanted to address is whether the abdominal expiratory muscles are significantly thicker and the pattern of thickness with the order $\mathrm{RA}>\mathrm{IO}>\mathrm{EO}>\mathrm{TA}$ is different in patients with simple weaning as compared to those with difficult or prolonged weaning.

\section{A IM}

To assess the expiratory abdominal muscle thickness pattern, diaphragmatic excursion (DE), diaphragmatic thickening fraction (DTF), and lung ultrasound score (LUS) in critically ill patients and their association with weaning pattern.

\section{Objectives}

The primary objective of the study is to determine the abdominal expiratory muscle thickness, the order of the thickness of abdominal expiratory muscles, diaphragmatic excursion and lung ultrasound score in patients undergoing weaning in the intensive care unit. The secondary objective was to estimate cut-off values of abdominal expiratory muscle thickness and diaphragm excursion distance to predict simple weaning.

\section{Materials and Methods}

\section{Study Design}

It was a single-center, prospective, cross-sectional observational study.

\section{Ethics}

Before the commencement of the study, Institutional Ethical Committee clearance was obtained (IEC:465/2020). Approval from the Clinical Trial Registry of India (CTRI) was then obtained (CTRI/2020/11/028895) before the first recruitment. Informed consent was taken from the patient's relative or legally authorized representative before recruitment.

\section{Study Population}

Eighty one patients aged between 18 and 80 years were included. Patients of either gender, who were on invasive mechanical ventilation and were put on spontaneous breathing trial (SBT) for the weaning process, were included. Patients who met the following criteria were put on SBT-Fraction of inspired oxygen $\left(\mathrm{FiO}_{2}<0.5\right)$, positive end-expiratory pressure (PEEP) $\leq 5 \mathrm{~cm} \mathrm{H}_{2} \mathrm{O}$, partial pressure of oxygen in arterial blood $\left(\mathrm{PaO}_{2}\right) / \mathrm{FiO}_{2}>200 \mathrm{~mm} \mathrm{Hg}$, respiratory rate $<35 /$ minute, tidal volume $>5 \mathrm{~mL} / \mathrm{kg}$, minute ventilation $<10 \mathrm{~L} /$ minute, no abnormality in electrolyte parameters, absence of hemodynamic instability, resolution of the initial cause of ventilator requirement and patients awake with the ability to cough.

Exclusion criteria included patients $<18$ years, patients with chest or abdominal trauma, distorted abdominal wall anatomy, patients with damage to the abdominal wall, patients with localized fluid collections in the abdomen, hernias, abdominal wall hematomas, inguinal masses, femoral hernias, abdominal surgeries, patients with any neuromuscular weakness, patients with any diaphragmatic disorders, pregnant patients. The SBT was terminated if rapid shallow breathing index was $>105$ breaths/ minute/L, RR $>35 /$ minute, $\mathrm{SpO}_{2}$ drop to $<90 \%$, the patient had evidence of respiratory distress with increased work of breathing, increase in heart rate $>20 \%$ from baseline or increase in systolic blood pressure $>180 \mathrm{~mm} \mathrm{Hg}$ or $<90 \mathrm{~mm} \mathrm{Hg}$. A flowchart describing the methodology is depicted (Flowchart 1).

\section{Data Collection}

In the patients who were put on spontaneous breathing trial (SBT) for weaning, data of age, gender, diagnosis, Acute Physiology, and Chronic Health Evaluation (APACHE II) score on intensive care unit (ICU) admission, Sequential Organ Failure Assessment (SOFA) score on admission were noted.

Flowchart 1: Flowchart depicting the methodology of the study

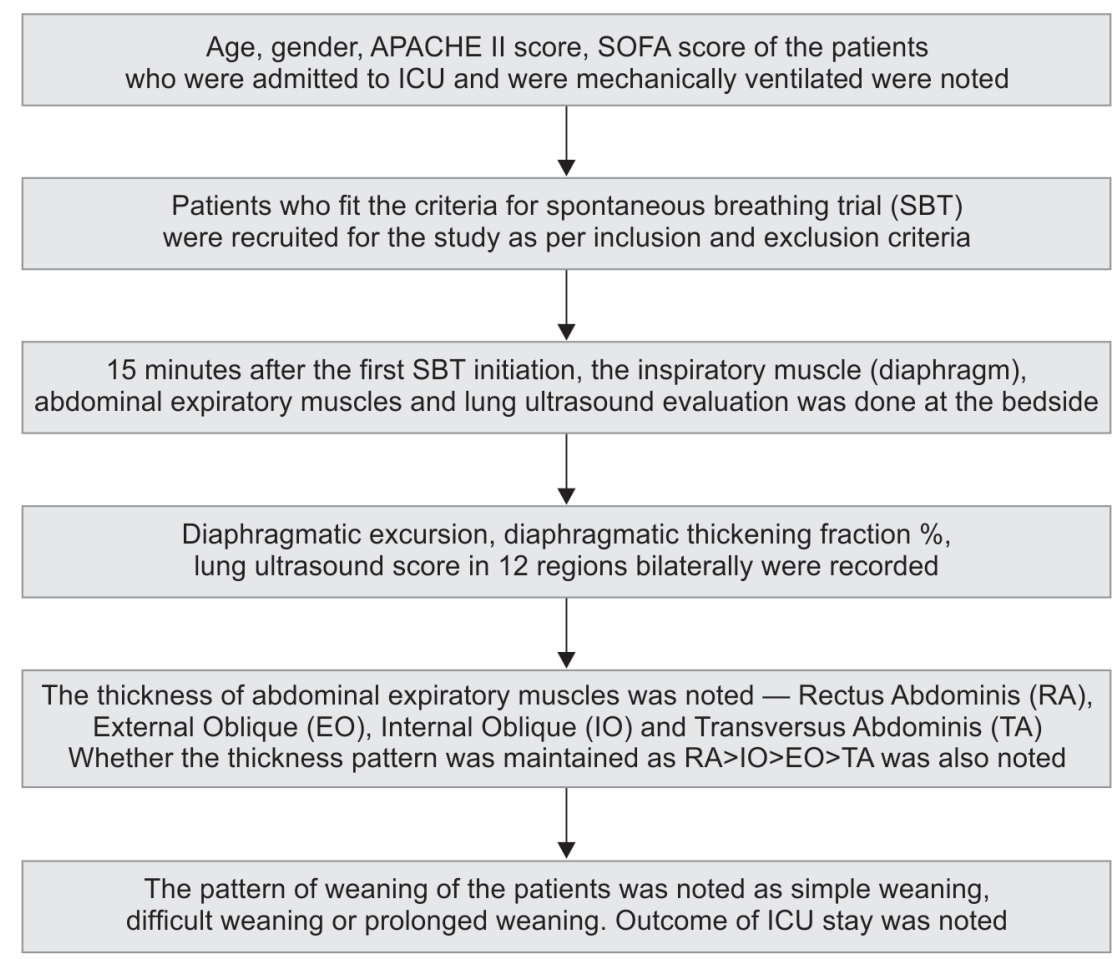




\section{Ultrasound Examination}

The bedside ultrasound examination was performed using Phillips machine model CX 50 (Phillips Healthcare, 3000 Minuteman Road, Andover, USA). A linear probe was used for calculating the thickness of expiratory abdominal muscles-RA, IO, EO, and TA. Ultrasound examination of RA was done by placing the linear probe horizontally about $2-3 \mathrm{~cm}$ above the umbilicus and $2-3 \mathrm{~cm}$ away from the midline. ${ }^{1}$ Ultrasound examination of the $\mathrm{EO}, \mathrm{IO}$, and TA was done by placing the linear probe horizontally at the anterior axillary line, approximately at the mid-point of the right costal margin and the iliac crest ${ }^{1}$ (Figs 1 and 2). Curvilinear probe was used for DE measurements (right side). The probe was placed in subcostal space in a horizontal fashion to measure the movement in M-mode. Lung ultrasound examination to calculate the LUS after examination of six lung regions on each side, with a maximum score of 36 , as described by Bouhemad et al. ${ }^{6}$ The LUS for each region was as follows: ${ }^{6}$

Score 0: Normal lung aeration, A-lines

Score 1: Moderate loss of lung aeration, B-lines which are well separated

Score 2: Severe loss of lung aeration, coalescent B-lines

Score 3: Complete loss of lung aeration, lung consolidation

A linear probe was used for DTF, at the zone of apposition between pleura and diaphragm at the mid-axillary line between the 8th and 10th intercostal space on the right side. ${ }^{7}$ The DTF percentage (DTF\%) was calculated as:

(Diaphragmatic thickness at end inspiration - Diaphragmatic thickness at end-expiration)/Diaphragmatic thickness at endexpiration $\times 100$.

Primary outcome was the weaning patterns which the patient had-simple, difficult, or prolonged. Weaning was categorized as simple weaning (initiation of weaning to successful extubation after first SBT), difficult weaning (patients failing initial SBT and requiring up to three SBTs or up to 7 days from first SBT for successful weaning), or prolonged weaning (requiring more than three SBTs and requiring 7 days after first SBT). ${ }^{7,8}$ Secondary outcomes were in terms of survival of ICU stay. The primary endpoint was the pattern of weaning, whether it was simple, difficult, or prolonged.

\section{Statistical Analysis}

Sample size calculation was done considering a proportion of $70 \%$ patients having simple weaning. ${ }^{9,10}$ Considering $10 \%$ relative error of proportion, confidence interval of 95 and $80 \%$ power of the study, sample size of 81 was calculated as follows:

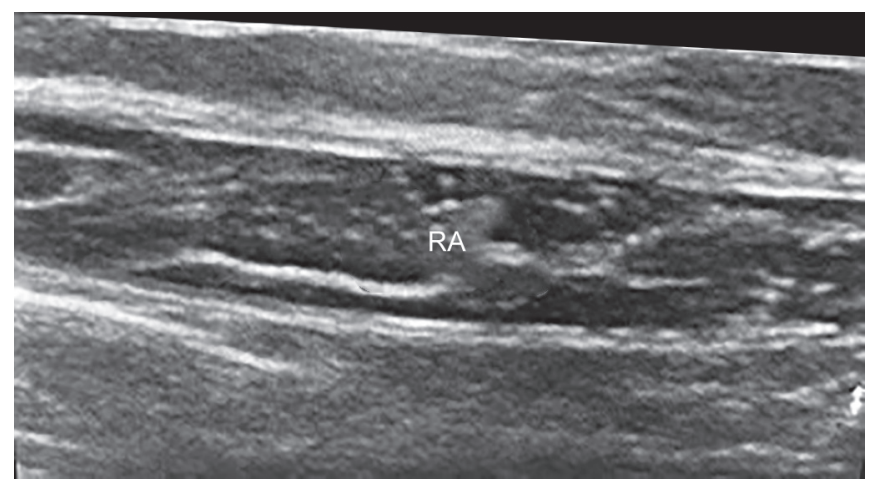

Fig. 1: Ultrasound depicting the rectus abdominis muscle (RA)

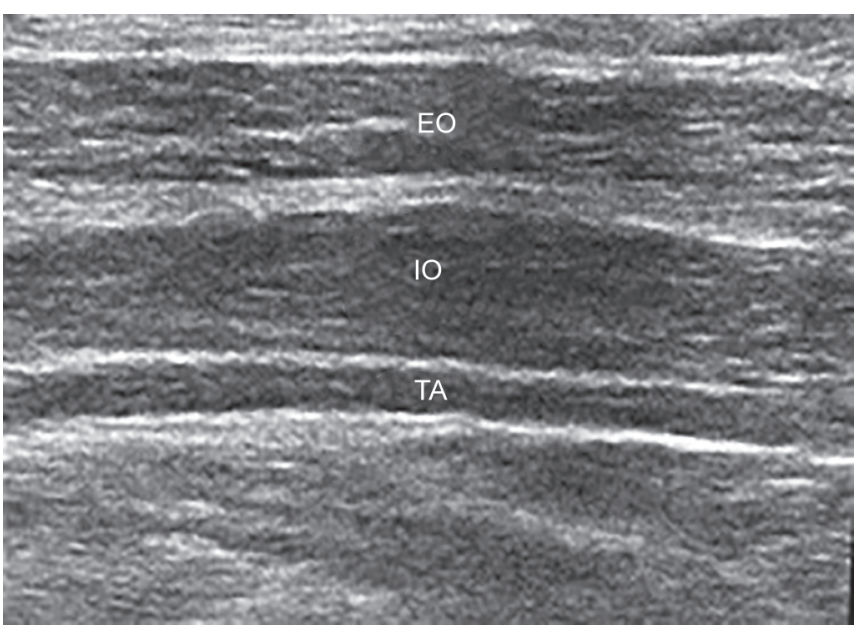

Fig. 2: Ultrasound depicting the external oblique (EO), internal oblique (IO), and transversus abdominis muscle (TA)

$Z(a / 2)=1.96$ for a confidence interval of $95 \%$, relative error $(E)$ is $10 \%$ Sample size $(n)=[Z(\alpha / 2) / E]^{2} \times P \times(1-P)=(1.96 / 0.1)^{2} \times(0.7) \times 0.3=$ 80.67 , rounded off to 81

Data analysis was done using statistical software IBM SPSS (Statistical Package for the Social Sciences) software (IBM Corp. Released 2012.IBM SPSS Statistics for Windows, version 22.0 Armonk, New York: IBM). Continuous variables were analyzed as mean and standard deviation (SD). To calculate the statistical differences in continuous variables between the simple weaning vs the difficult or prolonged weaning group, Independent Student's $t$-test was used. To calculate the statistical difference between categorical variables between two groups, Pearson's Chi-square test was used. A $p$-value of $<0.05$ was considered significant. The receiver operating characteristic (ROC) curves of the continuous variables helpful in predicting simple weaning to calculate the area under the curve (AUC) were plotted. The cut-off thickness of the four abdominal expiratory muscles-RA, IO, EO, TA, the DE, and DTF\% was derived from ROC curves, and sensitivity, specificity, $95 \%$ confidence interval, positive predictive value, negative predictive value, and diagnostic accuracy were calculated.

\section{Results}

Sixteen patients had a simple weaning pattern; 35 patients had a difficult weaning pattern and 30 had prolonged weaning. The age, APACHE II score, SOFA score on the day of admission to ICU and the mean and SD of all patients' ultrasound parameters on the day of first SBT are depicted (Table 1). There was a significant difference between the thickness of the abdominal expiratory muscles, RA, $I O, E O$, and TA between the patients in the simple weaning group and those in the difficult or prolonged weaning group (Table 2). There was a significant difference in the DE and LUS between the patients who had simple weaning and those who had either difficult or prolonged weaning (Table 2). The APACHE II score and SOFA score on admission were also significantly different between those with simple weaning and difficult/prolonged weaning (Table 2). Even though the DTF\% was more in those with simple weaning compared to those with difficult or prolonged weaning, it was not statistically significant (Table 2).

Regarding the pattern of abdominal expiratory muscle thickness following the order: $\mathrm{RA}>\mathrm{IO}>\mathrm{EO}>\mathrm{TA}$, the pattern was present in 
Table 1: Depiction of the mean and standard deviation (SD) of the age, APACHE II score, SOFA score and various measurements of the patients put on SBT as done by ultrasound

\begin{tabular}{lc}
\hline Variables of the patients $(\mathrm{N}=81)$ & Mean \pm SD \\
\hline Age (years) & $55.7 \pm 15.91$ \\
APACHE II & $15.43 \pm 6.63$ \\
SOFA & $6.22 \pm 3.53$ \\
Diaphragmatic excursion $(\mathrm{cm})$ & $1.67 \pm 0.4$ \\
Diaphragmatic thickening fraction \% & $27.28 \pm 7.53$ \\
Rectus abdominis thickness $(\mathrm{cm})$ & $0.62 \pm 0.18$ \\
Internal oblique thickness $(\mathrm{cm})$ & $0.46 \pm 0.18$ \\
External oblique thickness $(\mathrm{cm})$ & $0.32 \pm 0.1$ \\
Transversus abdominis thickness $(\mathrm{cm})$ & $0.24 \pm 0.07$ \\
Lung ultrasound score & $8.93 \pm 5.11$ \\
\hline
\end{tabular}

Table 2: Depiction of the difference in mean and standard deviation (SD) of the various parameters between those of difficult/prolonged weaning group versus those of simple weaning group. Independent Student's $t$ test ( $p<0.05$ is significant)

\begin{tabular}{lccc}
\hline & $\begin{array}{c}\text { Difficult or prolonged } \\
\text { veaning }(N=65)\end{array}$ & $\begin{array}{c}\text { Simple weaning } \\
(N=16)\end{array}$ & \\
\cline { 2 - 3 } $\begin{array}{l}\text { vatients in the study } \\
\text { patiean } \pm S D\end{array}$ & Mean $\pm S D$ & pvalue \\
\hline Age & $57.2 \pm 16.45$ & $49.63 \pm 12.14$ & 0.088 \\
APACHE II score & $16.42 \pm 6.45$ & $11.44 \pm 5.96$ & $<0.05$ \\
SOFA score & $6.68 \pm 3.58$ & $4.38 \pm 2.71$ & $<0.05$ \\
$\begin{array}{l}\text { Rectus abdominis } \\
\text { thickness (cm) }\end{array}$ & $0.59 \pm 0.16$ & $0.73 \pm 0.23$ & $<0.05$ \\
$\begin{array}{l}\text { Internal oblique } \\
\text { thickness (cm) }\end{array}$ & $0.43 \pm 0.14$ & $0.59 \pm 0.23$ & $<0.05$ \\
$\begin{array}{l}\text { External oblique } \\
\text { thickness (cm) }\end{array}$ & $0.30 \pm 0.08$ & $0.39 \pm 0.14$ & $<0.05$ \\
$\begin{array}{l}\text { Transversus } \\
\text { abdominis }\end{array}$ & $0.23 \pm 0.07$ & $0.27 \pm 0.07$ & $<0.05$ \\
thickness (cm) & & & \\
$\begin{array}{l}\text { Lung ultrasound } \\
\text { score (global) }\end{array}$ & $9.71 \pm 5.18$ & $5.75 \pm 3.32$ & $<0.05$ \\
$\begin{array}{l}\text { Diaphragmatic } \\
\text { excursion }\end{array}$ & $1.62 \pm 0.4$ & $1.89 \pm 0.35$ & $<0.05$ \\
$\begin{array}{l}\text { Diaphragmatic } \\
\text { thickening fraction }\end{array}$ & $0.38 \pm 0.49$ & $0.44 \pm 0.51$ & 0.703 \\
\hline
\end{tabular}

$75 \%$ of the patients who had simple weaning and $84.6 \%$ patients who had difficult or prolonged weaning, and there was no statistical difference between the two groups ( $p=0.362$, Pearson's Chi-square test) (Table 3). The AUC of the ROC plots and the confidence intervals (Cl) of the abdominal expiratory muscle thickness to predict simple weaning were as follows: RA [AUC 0.712, $p=0.009,95 \% \mathrm{Cl}(0.561$, 0.862 ), cut-off $0.638 \mathrm{~cm}$, sensitivity $68.8 \%$, specificity $64.6 \%$ ], IO [AUC $0.715, p=0.008,95 \% \mathrm{Cl}(0.558,0.872)$ cut-off $0.492 \mathrm{~cm}$, sensitivity $68.8 \%$, specificity $76.9 \%$ ], EO [AUC 0.718, $p=0.007,95 \% \mathrm{Cl}(0.567$, 0.869 ), cut-off $0.315 \mathrm{~cm}$, sensitivity $68.8 \%$, specificity $66.2 \%$ ], TA [AUC $0.689, p=0.019,95 \% \mathrm{Cl}(0.557,0.822)$, cut-off $0.253 \mathrm{~cm}$, sensitivity $62.5 \%$, specificity $64.6 \%$ ] (Fig. 3 ).

The AUC of DE for predicting simple weaning was 0.700 , $p=0.014,95 \% \mathrm{Cl}(0.552-0.847)$, cut-off $1.79 \mathrm{~cm}$, sensitivity $68.8 \%$, specificity $67.7 \%$ (Fig. 3). The AUC of DTF\% for predicting simple weaning was however not significant. (AUC 0.548, $p=0.553$ ) (Fig. 3).
Table 3: Depiction of the pattern of abdominal expiratory muscle thickness in the simple weaning versus difficult/prolonged weaning group. (RA, rectus abdominis; IO, internal oblique; EO, external oblique; $\mathrm{TA}$, transversus abdominis). Pearson's Chi-square test

\begin{tabular}{lccc}
\hline $\begin{array}{l}R A>I O>E O>T A \\
\text { thickness pattern }\end{array}$ & $\begin{array}{c}\text { Simple weaning } \\
(N=16)\end{array}$ & $\begin{array}{c}\text { Difficult/prolonged } \\
\text { weaning }(N=65)\end{array}$ & p value \\
\hline Not maintained & $4(25 \%)$ & $10(15.4 \%)$ & 0.362 \\
Maintained & $12(75 \%)$ & $55(84.6 \%)$ & \\
\hline
\end{tabular}

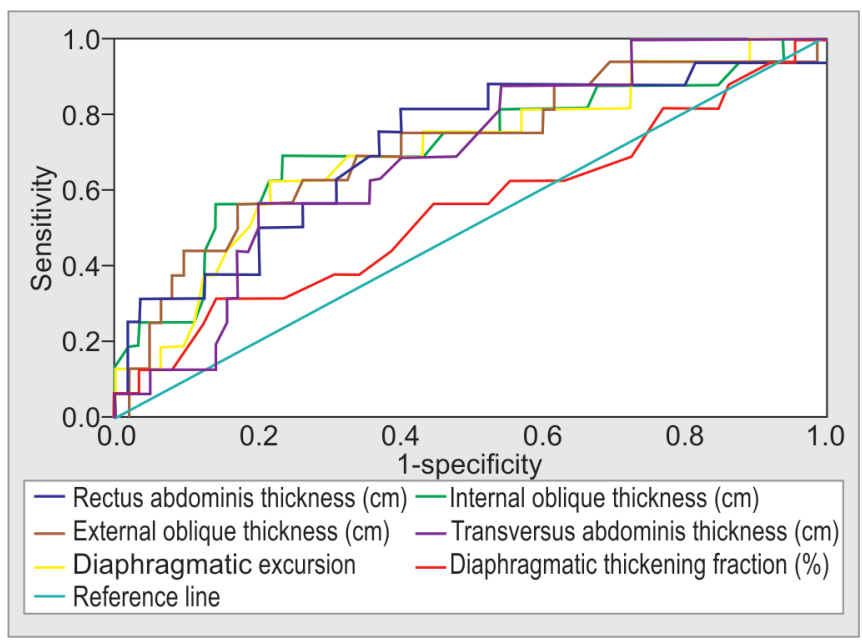

Fig. 3: Depiction of the Area Under Curve (AUC) as per Receiver Operating Characteristic (ROC) curve of the various variables rectus abdominis (RA), internal oblique (IO), external oblique (EO), diaphragmatic excursion (DE), and diaphragmatic thickening fraction (DTF)\% to predict simple weaning. Abdominal Expiratory MusclesRA [AUC $0.712, p=0.009,95 \% \mathrm{Cl}(0.561,0.862)$, cut-off $0.638 \mathrm{~cm}$ ], IO [AUC $0.715, p=0.008,95 \% \mathrm{Cl}(0.558,0.872)$ cut-off $0.492 \mathrm{~cm}$ ], EO [AUC $0.718, p=0.007,95 \% \mathrm{Cl}(0.567,0.869)$, cut-off $0.315 \mathrm{~cm}$ ], TA [AUC $0.689, p=0.019,95 \% \mathrm{Cl}(0.557,0.822)$, cut-off $0.253 \mathrm{~cm}$ ], DE [AUC 0.700 , $p=0.014,95 \% \mathrm{Cl}(0.552-0.847)$, cut-off $1.79 \mathrm{~cm}$ ], DTF\% (AUC 0.548, $p=0.553)$

The cut-off values, AUC, sensitivity, specificity, positive predictive value, negative predictive value and diagnostic accuracy of the four expiratory abdominal muscles thickness, DE and DTF\% to predict simple weaning are depicted in Table 4. The lung ultrasound score was $5.75 \pm 3.32$ in the simple weaning group, compared to $9.71 \pm 5.18$ in the difficult/prolonged weaning group $(p=0.005)$. Of the 65 patients in the difficult or prolonged weaning group, 14 patients required tracheostomy and 6 patients had failed to wean, requiring re-intubation. A total of 68 patients survived the ICU stay and 13 patients expired at the end of the ICU stay. The pattern of expiratory muscle thickness pattern $\mathrm{RA}>\mathrm{IO}>\mathrm{EO}>\mathrm{TA}$ was maintained both in the survival as well as expired group, and there was no significant difference in the expiratory abdominal muscle thickness pattern between the two groups-those who survived and those expired ( $p=0.160$, Pearson's Chi-Square test).

\section{Discussion}

Activation of abdominal expiratory muscles is beneficial during weaning, not only by improving the process of clearance of secretions from the airways, better cough, prevention of premature alveolar and airway closure but also by enhancing the inspiratory 
Table 4: Depiction of values of area under curve (AUC) as measured by receiver operating characteristic (ROC) curve, cut-off values for various parameters, $95 \%$ confidence interval $(\mathrm{Cl})$, sensitivity, specificity, positive predictive value (PPV), negative predictive value (NPV) diagnostic accuracy of the various parameters predicting simple weaning ( $p<0.05$ is significant)

\begin{tabular}{|c|c|c|c|c|c|c|c|c|c|}
\hline $\begin{array}{l}\text { Variables measured by } \\
\text { ultrasound }\end{array}$ & $A \cup C$ & $\begin{array}{l}\text { Cut-off value } \\
\qquad(\mathrm{cm})(\geq)\end{array}$ & $p$ value & $95 \% \mathrm{Cl}$ & Sensitivity & Specificity & $P P V$ & NPV & Diagnostic accuracy \\
\hline Rectus abdominis & 0.712 & 0.638 & 0.009 & $(0.561,0.862)$ & $68.8 \%$ & $64.6 \%$ & $32.4 \%$ & $89.4 \%$ & $65.43 \%$ \\
\hline Internal oblique & 0.715 & 0.492 & 0.008 & $(0.558,0.872)$ & $68.8 \%$ & $76.9 \%$ & $42.3 \%$ & $90.9 \%$ & $75.31 \%$ \\
\hline External oblique & 0.718 & 0.315 & 0.007 & $(0.567,0.869)$ & $68.8 \%$ & $66.2 \%$ & $33.3 \%$ & $89.6 \%$ & $66.67 \%$ \\
\hline Transversus abdominis & 0.689 & 0.253 & 0.019 & $(0.557,0.822)$ & $62.5 \%$ & $64.6 \%$ & $30.3 \%$ & $87.5 \%$ & $64.2 \%$ \\
\hline $\begin{array}{l}\text { Diaphragmatic } \\
\text { excursion }\end{array}$ & 0.700 & 1.79 & 0.014 & $(0.552,0.847)$ & $68.8 \%$ & $67.7 \%$ & $34.4 \%$ & $89.80 \%$ & $67.9 \%$ \\
\hline $\begin{array}{l}\text { Diaphragmatic } \\
\text { thickening fraction }\end{array}$ & 0.548 & $27.5 \%$ & 0.553 & $(0.379,0.717)$ & $56.3 \%$ & $55.4 \%$ & $21.6 \%$ & $100 \%$ & $28.40 \%$ \\
\hline
\end{tabular}

muscle capacity. ${ }^{1,11-14}$ The expiratory muscles enhance the inspiratory efforts by placing the diaphragm in a more cranial position before the next inspiration and assist in the development of more negative inspiratory pleural pressure. ${ }^{1,4}$ The abdominal expiratory muscles play a significant role in enhancing maximum expiratory pressure. ${ }^{1}$ Maximum expiratory pressure generated in turn has been correlated to expiratory muscle strength. ${ }^{1,14-16}$ Other parameters may also be used to evaluate the expiratory muscle strength, like the amount of gastric pressure developed during expiration (though it more specifically correlates to the strength of TA muscle) and the cough peak expiratory flow. ${ }^{1,17,18}$ However, these tests are often difficult to perform in critically ill ventilated patients to evaluate their expiratory muscle strength. The encouraging fact is that the TA thickness measured using ultrasound has been validated to correlate with pressure developed during the expiratory effort and also the extent of electrical activity generated in the muscle. ${ }^{1,19}$ The positive correlation between the thickness of diaphragm and its strength and the concurrence of the thickness of EO to the peak expiratory flow rate have been proven in previous studies. ${ }^{20,21}$ Thus we measured the thickness of RA, IO, EO, and TA using bed-side ultrasound and evaluated their role in the weaning pattern. The normal pattern of decreasing muscle thickness of the expiratory abdominal muscles bilaterally is $\mathrm{RA}>\mathrm{IO}>\mathrm{EO}>\mathrm{TA}$, which has been found in previous literature in healthy individuals. ${ }^{22}$

The order of this thickness of the abdominal muscles is an indicator of the equilibrium or stability within the muscle groups. It has been shown that any deviation from this pattern of muscle thickness may be ascribed to muscle atrophy of a particular expiratory abdominal muscle. ${ }^{22}$ The abdominal expiratory muscles' stability, equilibrium, and thickness all assist in increasing the abdominal pressure during expiration.,22 This in turn helps in the reduction of the expiratory transpulmonary pressure and optimal lung deflation. This prevents early airway collapse during expiration, assists in effective cough, increases expiratory flow, reduces chances of basal atelectasis. ${ }^{1}$ All these factors ultimately aid in successful weaning. ${ }^{1}$

We found the highest AUC (0.715) and diagnostic accuracy (75.31\%) of IO thickness for predicting simple weaning, which was even more than that of TA (AUC 0.689, diagnostic accuracy 64.2\%). $\mathrm{IO}$ is the second expiratory abdominal muscle (just after TA) to be recruited for expiratory efforts in critically ill ICU patients, whenever there is an increased workload on the inspiratory muscles. ${ }^{1,5}$ The findings of our study corroborate with that of a recently published study, where the authors found that IO and RA thickening fraction correlated to the expiratory pressure generated. ${ }^{23}$ The study concluded that reduced abdominal muscle thickening during cough leads to an enhanced probability of unsuccessful weaning from the ventilator. ${ }^{23}$ The importance of studying the abdominal expiratory muscles, which help in ventilator weaning, has also been emphasized before, where the investigators performed functional electrical stimulation of the abdominal muscles to help accentuate the weaning process. ${ }^{24}$ The authors had concluded that though functional electrical stimulation did not increase muscle thickness, the maneuver may be beneficial in reducing the length of ICU stay and ventilator days. ${ }^{24}$ However, another study had shown that electrical stimulation did increase RA thickness, which in turn assisted in weaning. ${ }^{25}$ The findings of the aforementioned study support the results of our study, where a thicker RA is associated with patients having simple weaning, compared to those with difficult or prolonged weaning. ${ }^{24}$ Thus, the importance of analyzing expiratory abdominal muscles has to be emphasized in the ICU, apart from our usual inspiratory muscle (mainly diaphragmatic) assessment. In our study, IO had the highest sensitivity (68.8\%) and specificity (76.9\%) among the abdominal expiratory muscles to predict simple weaning. However, it could not outperform the rapid shallow breathing index (RSBI), and literature shows that RSBI has higher sensitivity (84\%) in predicting weaning success, though the specificity is lower (70\%). ${ }^{26}$ The abdominal expiratory muscles are nevertheless an integral component of the respiratory muscle pump complex and should be evaluated during the weaning process. ${ }^{1}$

Regarding the pattern of thickness followed by the expiratory abdominal muscles, we did not find any statistical difference between the simple weaning group and the difficult or prolonged weaning group, where the pattern $\mathrm{RA}>\mathrm{IO}>\mathrm{EO}>\mathrm{TA}$ was maintained in both groups.

In a study done on six healthy male Italian patients, at FRC, the thicknesses of RA, IO, EO, TA were $11 \pm 4.3 \mathrm{~mm}, 11.1 \pm 3.8 \mathrm{~mm}$, $5.5 \pm 1.7 \mathrm{~mm}$, and $5.8 \pm 1.3 \mathrm{~mm}$, respectively. ${ }^{1}$ But cut-off values thickness of the abdominal muscles in our critically ill patients who had simple weaning were significantly lesser, being 6.38, 4.92, 3.15, and $2.53 \mathrm{~mm}$, respectively.

To the best of our knowledge, there are no studies on critically ill patients in India, elaborating the thickness of abdominal muscles which can predict weaning.

Considering the inspiratory muscle (diaphragm activity), we found a slightly lower cut-off for DE $(1.79 \mathrm{~cm})$ to predict simple weaning, than a previous study, where the authors concluded that DE $>2.2 \mathrm{~cm}$ has a high probability of weaning success. ${ }^{27}$ The DTF\% cut-off value in our study in the simple weaning was $27.5 \%$, which was similar to previous literature of $28 \%$, but was slightly lesser than 
$30 \%$ as described by DiNino et al. ${ }^{28}$ DTF\% correlates well with the trans-diaphragmatic pressure and diaphragm function. ${ }^{29,30}$

In our study, a significant finding is that the AUC of three expiratory muscles, RA, IO and EO, was much higher than the AUC of diaphragmatic excursion and diaphragmatic thickening fraction to predict simple weaning. This signifies the role of expiratory muscles in weaning, as it is when the inspiratory muscles are unable to handle the load imposed on them, that the expiratory muscles become more active. ${ }^{1}$ This situation is typically appreciated in critically ill patients.

The lung ultrasound score was significantly higher in the difficult or prolonged weaning group. But the score $(9.71 \pm 5.18)$ in our study was much lesser than the score of $16.5 \pm 4.2$ found by Soliman et al., in their patients with failed weaning group. ${ }^{31}$ The lower lung ultrasound score in our difficult or prolonged weaning patients could be because of factors like expiratory muscle thinning, with lesser diaphragmatic excursion may lead to an even lesser lung ultrasound score tolerated by the patients for weaning success. Lung ultrasound score is a reflection of the "lung wettability," and thus the conclusion by Seeley EJ that "A dry lung is a happy lung" is precise in critically ill patients being weaned, where the inspiratory load is high, the diaphragm is weakened, and expiratory muscles have an ever-increasing important role. ${ }^{6,32}$ The fact the diaphragmatic thinning and weakness start within 48 hours of mechanical ventilation is now known, and thinning occurs at a rate of $6 \%$ each day. ${ }^{33}$ This mandates that we also focus on expiratory muscles to predict weaning patterns.

Strengths of the study include that this was done to assess primarily the role of abdominal expiratory muscles in the weaning pattern, rather than the conventional inspiratory muscle (diaphragm) action only. The expiratory muscles are often overlooked for their role in weaning. We also compared the AUC of the expiratory muscles in predicting simple weaning to the AUC of the DE and DTF\% to signify the role of expiratory muscles in patients where the inspiratory load is high, as in critically ill. We also noted if the pattern of expiratory muscle thickness which is maintained in healthy individuals is also followed in the critically ill, and if that has an effect on the weaning pattern. Limitations of the study include that it was a single-center study. We did not measure the abdominal expiratory muscle thickening fraction of each of the muscles and assess their role in the weaning pattern. Also, the expiratory muscle thickness was measured on the day of the first SBT, and not during every subsequent SBT. We did not measure the change in thickness of the abdominal expiratory muscles on the day of SBT, as compared to their thickness on the day of admission. The evaluation of abdominal expiratory muscle thickness does not outperform the simple bedside tests like RSBI to predict simple weaning. Another limitation of the study is that the current sample size calculation is not accurate for the research question of evaluation of the abdominal expiratory muscle thickness and its association with weaning pattern.

\section{Conclusion}

In patients, mean and SD of the thickness of the abdominal expiratory muscle undergoing weaning in the critical care unit was $0.62 \pm 0.18 \mathrm{~cm}(\mathrm{RA}), 0.46 \pm 0.18 \mathrm{~cm}(\mathrm{IO}), 0.32 \pm 0.10 \mathrm{~cm}$ (EO), and $0.24 \pm 0.07 \mathrm{~cm}$ (TA). Abdominal expiratory muscles thickness of RA, IO, EO, TA being greater than $0.638,0.492,0.315$, and $0.253 \mathrm{~cm}$, respectively, predicted simple weaning pattern. Abdominal expiratory muscle thickness followed the pattern of RA $>$ IO $>\mathrm{EO}>\mathrm{TA}$ in both simple weaning and difficult or prolonged weaning groups. DE $>1.79 \mathrm{~cm}$ predicted simple weaning. LUS was significantly lower in the patients who had simple weaning pattern.

\section{ORCID}

Vedaghosh Amara (1) https://orcid.org/0000-0001-5296-2138

Vishwas P (1) https://orcid.org/0000-0002-6149-9509

Sagar S Maddani @ https://orcid.org/0000-0003-0700-0532

Srikant Natarajan @ https://orcid.org/0000-0002-2686-0397

Souvik Chaudhuri @ https://orcid.org/0000-0001-8392-2366

\section{References}

1. Shi ZH, Jonkman A, de Vries H, Jansen D, Ottenheijm C, Girbes A, et al. Expiratory muscle dysfunction in critically ill patients: towards improved understanding. Intensive Care Med 2019;45(8):1061-1071. DOI: 10.1007/s00134-019-05664-4.

2. Dres M, Goligher EC, Heunks LMA, Brochard LJ. Critical illnessassociated diaphragm weakness. Intensive Care Med 2017;43(10):14411452. DOI: 10.1007/s00134-017-4928-4.

3. Goligher EC, Fan E, Herridge MS, Murray A, Vorona S, Brace D, et al. Evolution of diaphragm thickness during mechanical ventilation. Impact of inspiratory effort. Am J Respir Crit Care Med 2015;192(9):1080-1088. DOI: 10.1164/rccm.201503-06200C.

4. Aliverti A, Cala SJ, Duranti R, Ferrigno G, Kenyon CM, Pedotti A, et al. Human respiratory muscle actions and control during exercise. J Appl Physiol (1985) 1997;83(4):1256-1269. DOI: 10.1152/ jappl.1997.83.4.1256.

5. Suzuki J, Tanaka R, Yan S, Chen R, Macklem PT, Kayser B. Assessment of abdominal muscle contractility, strength, and fatigue. Am J Respir Crit Care Med 1999;159:1052-1060. DOI: 10.1164/ajrccm.159.4.9803025.

6. Bouhemad B, Mongodi S, Via G, Rouquette I. Ultrasound for "lung monitoring" of ventilated patients. Anesthesiology 2015;122(2):437447. DOI: 10.1097/ALN.0000000000000558.

7. Samanta S, Singh RK, Baronia AK, Poddar B, Azim A, Gurjar M. Diaphragm thickening fraction to predict weaning-a prospective exploratory study. J Intensive Care 2017;5:62. DOI: 10.1186/s40560017-0258-4.

8. Navalesi P, Frigerio P, Patzlaff A, Häußermann S, Henseke P, Kubitschek M. Prolonged weaning: from the intensive care unit to home. Rev Port Pneumol 2014;20(5):264-272. DOI: 10.1016/j.rppneu.2014.04.006.

9. Heunks LM, van der Hoeven JG. Clinical review: the $A B C$ of weaning failure--a structured approach. Crit Care 2010;14(6):245. DOI: 10.1186/ cc9296.

10. Boles JM, Bion J, Connors A, Herridge M, Marsh B, Melot C, et al. Weaning from mechanical ventilation. Eur Respir J 2007;29(5):10331056. DOI: 10.1183/09031936.00010206.

11. Arora NS, Gal TJ. Cough dynamics during progressive expiratory muscle weakness in healthy curarized subjects. J Appl Physiol Respir Environ Exerc Physiol 1981;51(2):494-498. DOI: 10.1152/ jappl.1981.51.2.494.

12. Kravitz RM. Airway clearance in Duchenne muscular dystrophy. Pediatrics 2009;123(Suppl. 4):S231-S235. DOI: 10.1542/peds.20082952G.

13. Rhee MH, Lee DR, Kim LJ. Differences in abdominal muscle activation during coughing between smokers and nonsmokers. J Phys Ther Sci 2016;28(4):1147-1149. DOI: 10.1589/jpts.28.1147.

14. Su WL, Chen YH, Chen CW, Yang SH, Su CL, Perng WC, et al. Involuntary cough strength and extubation outcomes for patients in an ICU. Chest 2010;137(4):777-782. DOI: 10.1378/chest.07-2808.

15. Kutchak FM, Debesaitys AM, Rieder Mde M, Meneguzzi C, Skueresky AS, Forgiarini Junior LA, et al. Reflex cough PEF as a predictor of successful extubation in neurological patients. J Bras Pneumol 2015;41(1):358-364. DOI: 10.1590/S1806-37132015000004453.

16. Savi A, Teixeira C, Silva JM, Borges LG, Pereira PA, Pinto KB, et al. Gaucho Weaning Study G. Weaning predictors do not predict extubation 
failure in simple-to-wean patients. J Crit Care 2012;27(2):221-228. DOI: 10.1016/j.jcrc.2011.07.079.

17. Parthasarathy S, Jubran A, Tobin MJ. Cycling of inspiratory and expiratory muscle groups with the ventilator in airflow limitation. Am J Respir Crit Care Med 1998;158:1471-1478. DOI: 10.1164/ ajrccm.158.5.9802014.

18. Gobert F, Yonis H, Tapponnier R, Fernandez R, Labaune MA, Burle JF, et al. Predicting extubation outcome by cough peak flow measured using a built-in ventilator flow meter. Respir Care 2017;62(12):15051519. DOI: $10.4187 /$ respcare.05460.

19. Misuri G, Colagrande S, Gorini M, landelli I, Mancini M, Duranti R, et al. In vivo ultrasound assessment of respiratory function of abdominal muscles in normal subjects. Eur Respir J 1997;10(12):2861-2867. DOI: 10.1183/09031936.97.10122861.

20. McCool FD, Conomos P, Benditt JO, Cohn D, Sherman CB, Hoppin Jr FG. Maximal inspiratory pressures and dimensions of the diaphragm. Am J Respir Crit Care Med 1997;155(4):1329-1334. DOI: 10.1164/ ajrccm.155.4.9105075.

21. Ishida H, Kobara K, Osaka H, Suehiro T, Ito T, Kurozumi C, et al. Correlation between peak expiratory flow and abdominal muscle thickness. J Phys Ther Sci 2014;26(11):1791-1793. DOI: 10.1589/jpts.26.1791.

22. Tahan N, Khademi-Kalantari K, Mohseni-Bandpei MA, Mikaili S, Baghban AA, Jaberzadeh S. Measurement of superficial and deep abdominal muscle thickness: an ultrasonography study. J Physiol Anthropol 2016;35(1):17. DOI: 10.1186/s40101-016-0106-6.

23. Schreiber AF, Bertoni M, Coiffard B, Fard S, Wong J, Reid WD, et al. Abdominal muscle use during spontaneous breathing and cough in patients who are mechanically ventilated: a bi-center ultrasound study. Chest 2021:S0012-3692(21)01084-9. DOI: 10.1016/j.chest.2021.05.053.

24. McCaughey EJ, Jonkman AH, Boswell-Ruys CL, McBain RA, Bye EA, Hudson AL, et al. Abdominal functional electrical stimulation to assist ventilator weaning in critical illness: a double-blinded, randomised, sham-controlled pilot study. Crit Care 2019;23(1):261. DOI: 10.1186/ s13054-019-2544-0.
25. Dall'Acqua AM, Sachetti A, Santos LJ, Lemos FA, Bianchi T, Naue WS, et al. Use of neuromuscular electrical stimulation to preserve the thickness of the abdominal and chest muscles of critically ill patients: a randomized clinical trial. J Rehabil Med 2017;49(1):40-48. DOI: 10.2340/16501977-2168.

26. Mowafy SMS, Abdelgalel EF. Diaphragmatic rapid shallow breathing index for predicting weaning outcome from mechanical ventilation: comparison with traditional rapid shallow breathing index. Egypt J Anaesth 2019;35(1):9-17. DOI: 10.1016/ j.egja.2018.10.003.

27. Banerjee A, Mehrotra G. Comparison of lung ultrasound-based weaning indices with rapid shallow breathing index: are they helpful? Indian J Crit Care Med 2018;22(6):435-440. DOI: 10.4103/ijccm. IJCCM_331_17.

28. DiNino E, Gartman EJ, Sethi JM, McCool FD. Diaphragm ultrasound as a predictor of successful extubation from mechanical ventilation. Thorax 2014;69(5):423-427. DOI: 10.1136/thoraxjnl-2013-204111.

29. Dres $M$, Demoule A. Diaphragm dysfunction during weaning from mechanical ventilation: an underestimated phenomenon with clinical implications. Crit Care 2018;22(1):73. DOI: 10.1186/s13054018-1992-2.

30. Vivier E, Mekontso Dessap A, Dimassi S, Vargas F, Lyazidi A, Thille AW, et al. Diaphragm ultrasonography to estimate the work of breathing during non-invasive ventilation. Intensive Care Med 2012;38(5):796803. DOI: 10.1007/s00134-012-2547-7.

31. Soliman SB, Ragab F, Soliman RA, Gaber A, Kamal A. Chest ultrasound in predication of weaning failure. Open Access Maced J Med Sci 2019;7(7):1143-1147. DOI: 10.3889/oamjms.2019.277.

32. Seeley EJ. A dry lung is a happy lung: more supporting evidence. J Thorac Cardiovasc Surg 2015;149(1):321-322. DOI: 10.1016/ j.jtcvs.2014.09.021.

33. Grosu HB, Lee YI, Lee J, Eden E, Eikermann M, Rose KM. Diaphragm muscle thinning in patients who are mechanically ventilated. Chest 2012;142(6):1455-1460. DOI: 10.1378/chest.11-1638. 